\title{
Screening Drought Tolerant Rapeseed Cultivars Using Yield and Physiological Indices
}

\author{
Bahlanes Bakhtari ${ }^{1}$, Hooman Razi $^{i^{*}}$ and Seyed Abdolreza Kazemeini ${ }^{1}$ \\ ${ }^{1}$ Department of Crop Production and Plant Breeding, School of Agriculture, Shiraz University, \\ Shiraz, Iran.
}

\section{Authors' contributions}

This work was carried out in collaboration between all authors. Author BB performed the experiment, analyzed the data and wrote the initial draft of the manuscript. Author HR designed the study, supervised the whole work and wrote the final draft of the manuscript. Author SAK managed the field work and reviewed the final draft of the manuscript. All authors read and approved the final manuscript.

Article Information DOI: $10.9734 / A R R B / 2017 / 32938$ Editor(s):

(1) Ani A. Elias, Cornell University, USA. (2) George Perry, Dean and Professor of Biology, University of Texas at San Antonio, USA.

Reviewers: (1) Inge Gazendam, Agricultural Research Council Vegetable and Ornamental Plants, South Africa. (2) Badran E. Ayman, Desert Research Centre, Cairo, Egypt. (3) Mónica Guadalupe Lozano Contreras, National Institute of Forest Research Agricultural and Livestock (INIFAP), Mexico. Complete Peer review History: http://www.sciencedomain.org/review-history/19259

Original Research Article

Received 24 ${ }^{\text {th }}$ March 2017

Accepted $25^{\text {th }}$ May 2017

Published $31^{\text {st }}$ May 2017

\section{ABSTRACT}

Rapeseed (Brassica napus) is an important source of edible oil worldwide. Rapeseed production is adversely affected by water deficit stress in drought prone areas. This study aimed to evaluate drought tolerance in seventeen rapeseed cultivars using yield and physiological indicators. The field experiment using two irrigation regimes was conducted on a silty loam soil at the research station of School of Agriculture, Shiraz University, Shiraz, Iran. In each irrigation treatment, the seventeen rapeseed cultivars with different origins were grown in a randomized complete block design with three replications. The normal irrigation and drought stress treatments were irrigated when $40 \%$ and $70 \%$ of available soil water capacity were depleted, respectively. The results revealed highly significant differences among the rapeseed cultivars for seed yield, and the various yield and physiological indices. The yield under normal and drought stress conditions showed significant correlations with stress tolerance index (STI), mean productivity (MP), geometric mean 
productivity (GMP), harmonic mean productivity (HMP) and modified stress tolerance index (MSTI) implying these indicators are able to identify the high yielding drought tolerant rapeseed cultivars. Based on the reliable yield indices, the three-dimensional plot and biplot analysis showed that the cultivars Karaj 1, NK Octans and Modena were the high yielding drought tolerant rapeseed cultivars. Generally, the drought tolerant cultivars showed high relative water content (RWC) under stress conditions, however there was no strong association between drought tolerance and RWC.

Keywords: Brassica napus; water deficit; seed yield; Relative Water Content (RWC); Geometric Mean Productivity (GMP).

\section{INTRODUCTION}

Rapeseed (Brassica napus) is one of the world's major oilseed crops. Oil quantity and quality of rapeseed is negatively affected by drought in semi-arid regions. In particular, water deficit from flowering period to the end of seed set substantially reduce rapeseed yield [1]. Development of cultivars with improved drought tolerance is of great importance in rapeseed breeding programs. Rapeseed cultivars have shown significant variation in terms of drought tolerance [2,3] and [4]. Responses to drought stress depend on genotype, intensity and duration of water deficit, weather conditions, growth and developmental stages of rapeseed [5]. Screening drought tolerant genotypes is complex due to the difficulty to create welldefined and repeatable water stress conditions [6]. Thus, it is required to identify and utilize proper indicators to evaluate drought tolerance among plant genetic resources. Yield loss is known as a major indicator for screening drought tolerant genotypes. Various indices have been introduced to measure drought tolerance based on yield performance under stress and nonstress conditions [7]. Fischer and Maurer represented Stress Susceptibility Index (SSI) in which genotypes with lower SSI display higher levels of yield stability [8]. Rosielle and Hamblin [9] proposed stress tolerance (TOL), the yield difference between non-stress ( $Y p)$ and stress (Ys) environments, and mean productivity (MP) as the average of $Y p$ and $Y s$. According to these indices, genotypes with high MP and low TOL are recommended. Bouslama and Schapaugh [10] measured drought tolerance of a given genotype by calculating the ratio of $Y s$ to $Y p$ known as Yield Stability Index (YSI). Similar to TOL, YSI may select genotypes with low yield under non-stress environments. Stress Tolerance Index (STI) and Geometric Mean Productivity (GMP), introduced by Fernandez [11], are able to select drought tolerant genotypes with high yield potential. Modified Stress Tolerance Index (MSTI) was also suggested to improve the efficiency of STI [12]. Furthermore, yield index (YI) was defined as ratio of the yield of a given genotype under stressful conditions to the average yield of all genotypes in the same conditions [13] and [14]. Previous studies demonstrated that STI, MP, GMP and MSTI are appropriate indices for screening drought tolerant rapeseed genotypes [2,3,4] and [15]. Water use efficiency (WUE) for yield is another major component to take into account for plant production under water-limited conditions, although the relationship between WUE and drought tolerance is complex and variable [16].

Selection exclusively based on yield may not be efficient enough for drought tolerance improvement, as seed yield generally has low heritability particularly under stressful conditions [17]. Therefore, the effectiveness of screening drought tolerant genotypes may be enhanced by using those physiological attributes which are able to reflect different levels of drought tolerance in an easy and proper manner. Under water deficit conditions, different extents of water loss are observed among plant genotypes. Thus, physiological indices related to plant water status such as relative water content (RWC), relative water loss (RWL) and excised leaf water loss (ELWL) are widely used as the indicators associated with drought tolerance $[16,18,19]$ and [20]. This study was performed to evaluate drought tolerance in seventeen rapeseed cultivars using yield and physiological indicators.

\section{MATERIALS AND METHODS}

The field experiment was performed on a silty loam soil at the research station of School of Agriculture, Shiraz University, Shiraz, Iran $\left(29^{\circ} 50^{\prime} \mathrm{N}, 5^{\circ} 46^{\prime} \mathrm{E}\right.$, Altitude $1810 \mathrm{~m}$ above sea level) during 2011-2012 growing season. Soil water content at field capacity and wilting point were measured in the root zone to estimate plant available water capacity of the soil. The experiment consisted of two irrigation regimes. The normal irrigation and drought stress 
treatments were irrigated when $40 \%$ and $70 \%$ of available soil water capacity were depleted, respectively. In each irrigation treatment, the seventeen rapeseed cultivars (1: SLM 046, 2: Opera, 3: Talaye, 4: Modena, 5: Karaj 1, 6: Karaj 3, 7: Zarfam, 8: Okapi, 9: Savanna, 10: Cooper, 11: Adriana, 12: Champlain, 13: NK Karibik, 14: NK Aviator, 15: NK Octans, 16: Licord and 17: Elite) with different origins were grown in a randomized complete block design with three replications. Each plot consisted of 6 rows spaced $30 \mathrm{~cm}$ apart and $3 \mathrm{~m}$ in length. The drought stress was carried out from flowering to maturity. Total precipitation was $258 \mathrm{~mm}$ during the experiment; however, no rainfall occurred during drought stress period. Applied water was measured in each irrigation regime. In order to implement irrigation schedules according to the irrigation regimes, soil water content was regularly measured at depths of $0-30 \mathrm{~cm}$ and $30-$ $60 \mathrm{~cm}$ using gravimetric method [21] by weighing the soil samples before and after oven-drying at $105^{\circ} \mathrm{C}$ for $24 \mathrm{~h}$ and calculating their original moisture content.

Four central rows per plot were harvested to measure seed yield. Also, water use efficiency (WUE) was calculated as the ratio of seed yield per unit area to amount of water applied [22], for each of the cultivars at the end of growing season. The yield-based drought tolerance indices were calculated using the following formulas, in which $Y p$ and $Y s$ represent yield of a given cultivar under non-stress and stressful conditions; and $\bar{Y} \mathrm{p}$ and $\bar{Y}$ s denote mean yield of all cultivars under non-stress and stress conditions, respectively.

Stress Susceptibility Index (SSI) =

$$
\frac{1-\frac{Y_{S}}{Y_{p}}}{1-\frac{\bar{Y}_{S}}{\bar{Y}_{p}}}
$$

$$
\text { Tolerance }(\mathrm{TOL})=Y p-Y_{s}
$$

Mean Productivity $(\mathrm{MP})=\frac{Y s+Y p}{2}$

Yield Index $(\mathrm{YI})=\frac{Y_{S}}{\bar{Y}_{S}}$

Yield Stability Index (YSI)

$$
\begin{aligned}
& \text { Stress Tolerance Index }(\mathrm{STI})= \\
& \frac{Y p \times Y s}{\bar{Y}_{p}^{2}} \\
& \text { Geometric Mean Productivity (GMP) } \\
& =\sqrt{Y s \times Y p}
\end{aligned}
$$

Harmonic Mean Productivity (HMP)

$$
=\frac{2 Y p \times Y s}{Y p+Y s}
$$

Modified Stress Tolerance Index (MSTI)

$$
=\frac{Y_{S}^{2}}{\bar{Y}_{S}^{2}} S T I
$$

Five leaf samples per plot were collected at silique formation stage to measure RWC according to the method described by Barrs [23]. Fresh leaves were immediately weighed to obtain fresh weight (FW) and then floated in distilled water for $8 \mathrm{~h}$, blot-dried and weighed to get turgid weight (TW). After that, the leaf samples were oven dried at $80^{\circ} \mathrm{C}$ for $24 \mathrm{~h}$ to obtain dry weight (DW). In addition, at the same developmental stage, another five leaf samples per plot were taken to determine RWL and ELWL according to the corresponding protocols [18, 19]. Fresh weight of the leaf samples was obtained. The leaf samples were further weighed after drying in the incubator at $25^{\circ} \mathrm{C}$ for 2 hour (W1), $4 \mathrm{~h}$ (W2) and $6 \mathrm{~h}$ (W3). T2-T1 is the time interval between two consecutive weight measurements $(2 \mathrm{~h})$. Finally, dry weight of the leaf samples was measured after oven-drying at $80^{\circ} \mathrm{C}$ for $24 \mathrm{~h}$. The physiological indices were calculated using the following equations:

$$
\begin{aligned}
& \text { Relative Water Content (RWC) } \\
& =\frac{F W-D W}{T W-D W}
\end{aligned}
$$

Relative Water Loss (RWL)

$$
=\frac{(F W-W 1)+(W 1-W 2)+(W 2-W 3)}{3 D W(T 2-T 1)}
$$

Excised Leaf Water Loss (ELWL)

$$
=\frac{F W-W 3}{F W-D W}
$$

Analysis of variance was performed to examine the effect of the rapeseed cultivars on the yield and physiological indices. Means comparisons were made using Tukey's HSD test at $P<.05$. 
Correlation coefficients were obtained to determine the relationships among the indices and the seed yield under both conditions using SAS 9.1 (SAS Institute Inc., Cary, NC). The high yielding drought tolerant cultivars were identified using biplot diagram obtained based on principal component analysis (PCA).

\section{RESULTS AND DISCUSSION}

It is well documented that drought stress, particularly at reproductive stage, causes a significant reduction in rapeseed yield $[2,3,4,15$, 24] and [25]. Accordingly, in this study, the results of analysis of variance (Table 1) showed that seed yield of the rapeseed cultivars significantly decreased under drought stress conditions. It is noteworthy that the drought stress experiment received $540 \mathrm{~mm}$ water which was $37 \%$ less than that of the normal experiment. The results of analysis of variance (Table 2) revealed highly significant differences between the rapeseed cultivars for seed yield under both normal and drought stress conditions. In addition, a significant variation was observed among the cultivars for yield-based drought tolerance indices facilitating selection for drought tolerance (Table 2). The means of yield under both conditions as well as various drought tolerance indices of the rapeseed cultivars are shown in Table 3. The results showed that Karaj1 cultivar had the maximum seed yield under both normal and drought-stress conditions. On the other hand, Okapi and Opera cultivars showed the minimum seed yield under normal and drought-stress conditions, respectively. Some cultivars such as Licord and Adrianna with high yield under normal conditions showed a dramatic yield reduction under drought stress conditions implying that selection for drought tolerance solely based on yield potential may not be sufficient.
The drought tolerance indices (Table 3 ) were used to provide a more accurate estimation of drought tolerance than seed yield under either normal or stressful environments; however, the indices ranked the rapeseed cultivars in different orders. According to MP, YI, GMP, HMP, STI and MSTI, Karaj1 and NK Octans were known to be the drought tolerant cultivars. Also, STI, MSTI, MP and GMP ranked the cultivars in a similar order indicating that they are comparable for selection of drought tolerant cultivars. These results were in agreement with previous reports showing similar trends for these indices $[4,15,26]$ and [27]. Based on SSI, TOL and YSI, Okapi was the most drought tolerant cultivar, whilst Opera and Licord were identified as the drought sensitive cultivars.

In order to select the high yielding drought tolerant rapeseed cultivars, those indices which were significantly correlated with the yield under normal and drought stress conditions ( $Y p$ and Ys) were taken into account as the reliable indicators. The correlation coefficients between $Y p$, Ys and the drought tolerance indices were shown in Table 4. Yp showed positive and significant correlations with the indices other than SSI and YSI. Furthermore, significant correlation coefficients were obtained between Ys and the indices except TOL. As a result, the correlation coefficients implied that MP, GMP, HMP, STI and MSTI were the indicators able to identify the high yielding drought tolerant rapeseed cultivars. This finding was consistent with the previous studies which suggested STI, MP and GMP for screening drought tolerant genotypes in rapeseed [2,3,4] and [15], and some other crops such as wheat $[23,25]$ and [26], maize [27] and rice [28]. Moreover, MSTI was known to be a good index to identify drought tolerant genotypes in rapeseed [4] and [29], wheat [30] and maize [27].

Table 1. Combined analysis of variance for yield and physiological indices of the seventeen rapeseed cultivars grown in normal and drought stress environments

\begin{tabular}{|c|c|c|c|c|c|c|}
\hline \multirow[t]{2}{*}{ SOV } & \multirow[t]{2}{*}{ df } & \multicolumn{5}{|c|}{ Mean squares } \\
\hline & & RWC & RWL & ELWL & WUE & Yield \\
\hline irrigation & 1 & 1841.7 & $0.09^{\pi *}$ & $0.004^{\mathrm{ns}}$ & 33.74 & 73022152.8 \\
\hline Block $\times$ irrigation & 4 & 13.71 & 0.003 & 0.001 & 1.6 & 686616.9 \\
\hline Cultivar & 16 & $59.09^{* *}$ & $0.013^{x *}$ & $0.007^{* \pi}$ & $3.25^{\star x}$ & $1724122.7^{* \pi}$ \\
\hline Cultivar $\times$ irrigation & 16 & $39.5^{\pi \times}$ & $0.007^{* \pi}$ & $0.008^{* \pi}$ & $1.12^{x \pi}$ & $734111.4^{\star \pi}$ \\
\hline Error & 64 & 9.35 & 0.002 & 0.001 & 0.02 & 11554.5 \\
\hline CV (\%) & & 3.7 & 24.5 & 16.7 & 5.5 & 5.2 \\
\hline
\end{tabular}


Table 2. Analysis of variance for seed yield under normal and drought stress conditions and drought tolerance indices

\begin{tabular}{|c|c|c|c|c|c|c|c|c|c|c|c|c|}
\hline \multirow[t]{2}{*}{ SOV } & \multirow[t]{2}{*}{ df } & \multicolumn{11}{|c|}{ Mean squares } \\
\hline & & $Y p$ & Ys & SSI & TOL & MP & $\mathbf{Y} \mathbf{I}$ & YSI & STI & GMP & HMP & MSTI \\
\hline Cultivar & 16 & $1950191.8^{* *}$ & $508042.3^{\text {*x }}$ & $0.2^{\pi \pi}$ & $1468222.7^{*}$ & $862061.3^{\text {** }}$ & $0.36^{* *}$ & $0.06^{* *}$ & $0.18^{* \pi}$ & $783639^{* *}$ & $775905.6^{* \pi}$ & $2.05^{\times \pi}$ \\
\hline Error & 34 & 15217.5 & 7891.4 & 0.003 & 17767.8 & 46822 & 0.004 & 0.002 & 0.002 & 52810.4 & 57338 & 0.01 \\
\hline CV (\%) & & 4.7 & 7.4 & 6.1 & 7.8 & 10.6 & 6.6 & 11.2 & 11.4 & 6.1 & 12.5 & 14.5 \\
\hline
\end{tabular}

MP: Mean Productivity; YI: Yield Index; YSI: Yield Stability Index; STI: Stress Tolerance Index; GMP. Geometric Mean Productivity; HMP: Harmonic Mean Productivity; MSTI: Modified Stress Tolerance Index

Table 3. Drought tolerance indices and seed yield under normal and drought stress conditions measured in the seventeen rapeseed cultivars

\begin{tabular}{|c|c|c|c|c|c|c|c|c|c|c|c|}
\hline Cultivar & Yp (Kg/ha) & Ys (Kg/ha) & SSI & TOL & MP & $\mathrm{YI}$ & YSI & STI & GMP & HMP & MSTI \\
\hline SLM 046 & 2240.99 & 743.58 & 1.14 & 1497.41 & 1492.28 & 0.62 & 0.33 & 0.20 & 1290.54 & 1116.22 & 0.07 \\
\hline Opera & 2783.71 & 594.57 & 1.34 & 2189.14 & 1689.14 & 0.50 & 0.21 & 0.19 & 1283.68 & 977.32 & 0.04 \\
\hline Talaye & 3094.81 & 1100.74 & 1.10 & 1994.07 & 2097.78 & 0.92 & 0.35 & 0.40 & 1840.03 & 1616.25 & 0.34 \\
\hline Modena & 3851.44 & 1600.00 & 1.00 & 2251.44 & 2725.72 & 1.34 & 0.41 & 0.73 & 2480.78 & 2258.33 & 1.33 \\
\hline Karaj 1 & 4064.69 & 2119.01 & 0.82 & 1945.68 & 3091.85 & 1.78 & 0.52 & 1.03 & 2930.91 & 2779.08 & 3.29 \\
\hline Karaj 3 & 1668.15 & 1105.18 & 0.58 & 562.97 & 1386.67 & 0.93 & 0.65 & 0.22 & 1355.26 & 1324.80 & 0.19 \\
\hline Zarfam & 2062.96 & 766.67 & 1.07 & 1296.30 & 1414.82 & 0.64 & 0.37 & 0.18 & 1256.94 & 1116.94 & 0.07 \\
\hline Okapi & 1568.40 & 1257.28 & 0.34 & 311.11 & 1412.84 & 1.06 & 0.79 & 0.23 & 1403.36 & 1393.97 & 0.26 \\
\hline Savanna & 2945.24 & 1762.69 & 0.68 & 1182.55 & 2353.97 & 1.48 & 0.59 & 0.62 & 2277.68 & 2203.96 & 1.36 \\
\hline Cooper & 2332.10 & 889.63 & 1.05 & 1442.47 & 1610.87 & 0.75 & 0.38 & 0.24 & 1439.68 & 1286.92 & 0.13 \\
\hline Adriana & 3988.15 & 1284.86 & 1.15 & 2703.29 & 2636.50 & 1.08 & 0.32 & 0.61 & 2262.80 & 1942.46 & 0.73 \\
\hline Champlain & 2138.27 & 1076.30 & 0.85 & 1061.98 & 1607.29 & 0.90 & 0.50 & 0.27 & 1516.27 & 1430.57 & 0.24 \\
\hline NK Karibik & 2951.85 & 1135.06 & 1.05 & 1816.79 & 2043.46 & 0.95 & 0.38 & 0.40 & 1828.59 & 1637.01 & 0.36 \\
\hline NK Aviator & 2700.00 & 1254.45 & 0.91 & 1445.55 & 1977.22 & 1.05 & 0.46 & 0.40 & 1837.60 & 1708.49 & 0.44 \\
\hline NK Octans & 3890.37 & 1632.84 & 0.99 & 2257.53 & 2761.60 & 1.37 & 0.41 & 0.76 & 2518.83 & 2297.86 & 1.45 \\
\hline Licord & 3609.38 & 663.71 & 1.39 & 2945.68 & 2136.55 & 0.56 & 0.18 & 0.28 & 1545.14 & 1119.25 & 0.08 \\
\hline Elite & 3126.67 & 1262.84 & 1.02 & 1863.83 & 2194.76 & 1.06 & 0.40 & 0.47 & 1986.54 & 1798.25 & 0.53 \\
\hline HSD (0.05) & 377.40 & 271.70 & 0.18 & 405.90 & 658.90 & 0.20 & 0.15 & 0.15 & 699.80 & 729.20 & 0.34 \\
\hline
\end{tabular}

Yp: Yield under normal conditions; Ys: Yield under drought stress conditions; SSI: Stress Susceptibility Index; TOL:Tolerance; MP: Mean Productivity; YI: Yield Index;

YSI: Yield Stability Index; STI: Stress Tolerance Index; GMP: Geometric Mean Productivity; HMP: Harmonic Mean Productivity; MSTI: Modified Stress Tolerance Index;

Tukey HSD, $p<0.05$ 
Table 4. Correlation coefficients among seed yield under normal and drought stress conditions and drought tolerance indices

\begin{tabular}{|c|c|c|c|c|c|c|c|c|c|c|}
\hline $0.63^{m x}$ & $0.80^{\prime \prime m}$ & $0.49^{\prime}$ & 0.45 & $0.68^{m x}$ & 0.82 & -0.45 & $0.94^{-\pi x}$ & $0.85^{m}$ & 0.49 & $Y p$ \\
\hline $0.89^{\text {*x }}$ & $0.90^{* x}$ & $1.0^{\mathrm{xi}}$ & $-0.50^{x}$ & $0.96^{x \pi}$ & $0.89^{x=}$ & $0.50^{x}$ & $0.75^{\text {xx }}$ & -0.01 & Ys & \\
\hline 0.20 & 0.39 & -0.01 & $0.81^{* *}$ & 0.22 & 0.41 & $-0.81^{* \pi}$ & $0.64^{\approx \pi}$ & TOL & & \\
\hline $0.82^{* \pi}$ & $0.95^{x \times}$ & $0.75^{* \pi}$ & 0.14 & $0.88^{\star \pi x}$ & $0.96^{\star x}$ & -0.14 & MP & & & \\
\hline 0.23 & 0.09 & $0.50^{*}$ & $-1.0 \times$ & 0.27 & 0.08 & YSI & & & & \\
\hline $0.89^{* \pi}$ & $0.99^{* x}$ & $0.89^{\text {** }}$ & -0.08 & $0.97^{\star \pi x}$ & GMP & & & & & \\
\hline $0.91^{* *}$ & $0.97^{* *}$ & $0.96^{\text {*x }}$ & -0.27 & HMP & & & & & & \\
\hline-0.23 & -0.09 & $-0.50^{*}$ & SSI & & & & & & & \\
\hline $0.89^{* \pi}$ & $0.90^{* x}$ & YI & & & & & & & & \\
\hline $0.93^{*}$ & STI & & & & & & & & & \\
\hline$\frac{\mathrm{MSTI}}{\mathrm{V} \cdot \mathrm{V}}$ & 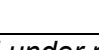 & & & & & & & & & \\
\hline
\end{tabular}

Table 5. Principal component analysis for seed yield under normal and drought stress conditions as well as drought tolerance indices of seventeen rapeseed cultivars

\begin{tabular}{lll}
\hline Index & PC1 & PC2 \\
\hline Yp & 0.29 & 0.32 \\
Ys & 0.34 & -0.19 \\
SSI & -0.06 & 0.51 \\
TOL & 0.13 & 0.49 \\
MP & 0.35 & 0.16 \\
YI & 0.34 & -0.19 \\
YSI & 0.05 & -0.52 \\
STI & 0.37 & 0.02 \\
GMP & 0.37 & 0.03 \\
MSTI & 0.34 & -0.05 \\
HMP & 0.36 & -0.06 \\
Eigen value & 7.22 & 3.52 \\
Relative variance (\%) & 65.70 & 32 \\
Cumulative variance (\%) & 65.70 & 97.70 \\
\hline Yp: Yield under normal conditions; Ys: Yield under \\
drought stress conditions; SSI: Stress Susceptibility \\
Index; TOL: Tolerance; MP: Mean Productivity; YI: \\
Yield Index; YSI: Yield Stability Index; STI: Stress \\
Tolerance Index; GMP: Geometric Mean Productivity; \\
\multicolumn{2}{c}{ MSTI: Modified Stress Tolerance Index; } \\
\multicolumn{2}{c}{ HMP: Harmonic Mean Productivity }
\end{tabular}

The high yielding drought tolerant rapeseed cultivars were identified using the threedimensional plot (Fig. 1) which represented interrelationships among $\mathrm{Yp}, \mathrm{Ys}$ and GMP identified as the useful and reliable drought tolerance indicators in this study and also previous studies [2,3,4] and [15]. According to the three-dimensional plot, the cultivars fell into four groups namely $A$ to $D$, as proposed by Fernandez [11]. The group A contained the cultivars Karaj 1, NK Octans, Savanna and
Modena which had drought tolerance and high yield under both normal and drought stress environments. The cultivars within group $B$ including Adriana, Elite, NK Karibik, Talaye and Licord showed high yield only under normal conditions. The remaining cultivars fell within group $D$ indicating that they were low yielding cultivars under both environments.

Principal component analysis was used to reduce the number of drought tolerance indicators to a set of uncorrelated components. The biplot diagram (Fig. 2) was depicted based on the first and second principal components which totally accounted for $97.70 \%$ of variation. The first component (PC1) explained $65.7 \%$ of total variation (Table 5). This component showed positive correlations with Ys, Yp, MP, GMP, YI, HMP, STI and MSTI. Therefore, PC1 was called as the yield potential and drought tolerance. The cultivars with high positive values of PC1 on the biplot diagram had high yield under both normal and stress conditions. The second component (PC2) explained $32 \%$ of total variation (Table 5). PC2 had high positive correlations with TOL, SSI and $Y p$ as well as a negative correlation with Ys. Thus, PC2 was named as the stress susceptibility component able to separate drought tolerant cultivars from drought sensitive cultivars. Altogether, the cultivars which exhibited high PC1 and low PC2 were presumed to be appropriate for both normal and drought stress environments [23]. Consequently, Karaj 1, NK Octans, Modena and Savanna were known as the high yielding drought tolerant rapeseed cultivars. On the other hand, Opera and Licord were the low yielding drought sensitive rapeseed cultivars (Fig. 2). The results of biplot analysis 
and three-dimensional plot were in accordance with each other. Biplot analysis revealed strong positive associations between seed yield in both water conditions and STI, MP, GMP, MSTI, HMP and $\mathrm{YI}$ as evidenced by the acute angles between their vectors. This finding was consistent with the results obtained from the correlation coefficients (Table 4). Several studies have utilized biplot analysis on the basis of the first two principal components to identify drought tolerant genotypes of crop species $[2,15,23,26$, 28] and [30].

The maintenance of stable water content is essential for normal growth and high yield of crops. Thus, leaf water status may be a potential indicator of drought tolerance in crops. Any disruption in leaf turgor pressure may subsequently have an adverse impact on physiological processes such as stomatal opening and photosynthesis [31]. In this experiment, leaf water status of the rapeseed cultivars was evaluated through three physiological indices including RWC, ELWL and RWL. High RWC and low RWL and ELWL have been suggested as desirable indicators for leaf water status [32]. The results of variance analysis (Table 1) showed significant differences among the rapeseed cultivars for all the physiological indices measured in both normal and stressful conditions. Drought stress treatment had no significant effect on ELWL probably because the direction of ELWL changes due to drought stress was not consistent across the cultivars. On the other hand, drought stress caused significant differences in RWL, which generally had a trend similar to ELWL, over the cultivars. According to Table 6, the cultivars NK Octans and Zarfam showed the highest levels of water loss in their leaves under drought stress conditions in terms of RWL, whilst Talaye and Karaj 3 had the lowest RWL under such conditions. The highest and lowest ELWL under drought stress conditions were recorded for the cultivars Zarfam and Talaye, respectively (Table 6). In general, no obvious relationships were observed between these two physiological indices and drought tolerance measured by yieldbased indices. Similar to the previous reports [33] and [34], RWC significantly declined during drought stress conditions. The rapeseed cultivars showed different levels of RWC reduction under stressful conditions. The cultivars Modena and NK Octans which were known as the drought tolerant cultivars based on yield-based indices, were among the cultivars with minimum RWC change due to drought stress (Table 6). In addition, the drought tolerant cultivars

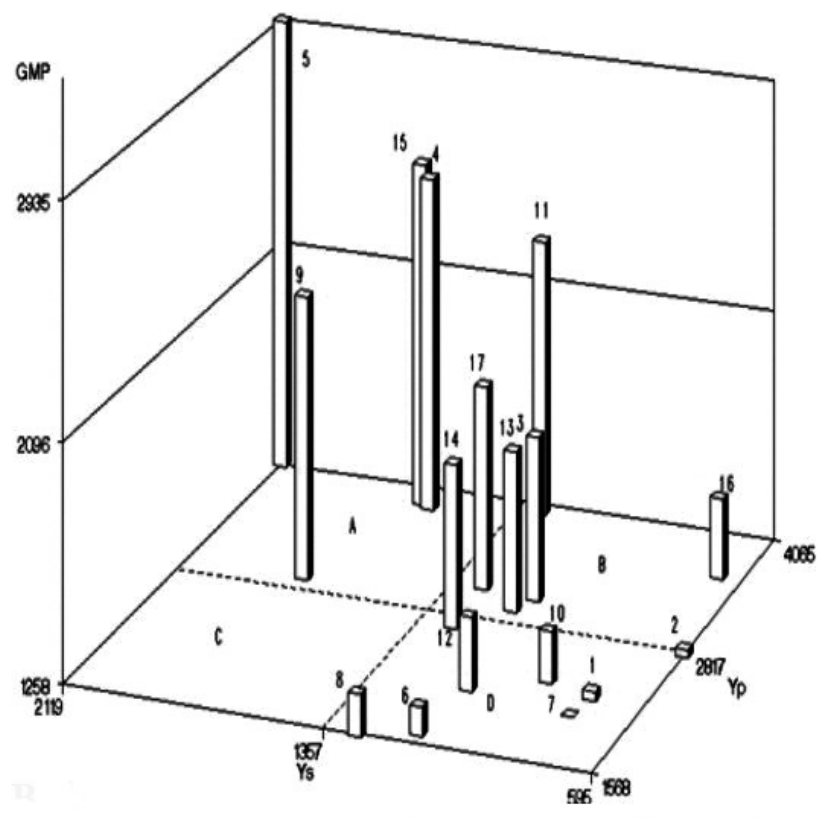

Fig. 1. Three-dimensional plot among seed yield under normal and drought stress conditions (Yp and Ys) and Geometric Mean Productivity (GMP). 1: SLM 046, 2: Opera, 3: Talaye, 4: Modena, 5: Karaj 1, 6: Karaj 3, 7: Zarfam, 8: Okapi, 9: Savanna, 10: Cooper, 11: Adriana, 12: Champlain, 13: NK Karibik, 14: NK Aviator, 15: NK Octans, 16: Licord and 17: Elite 


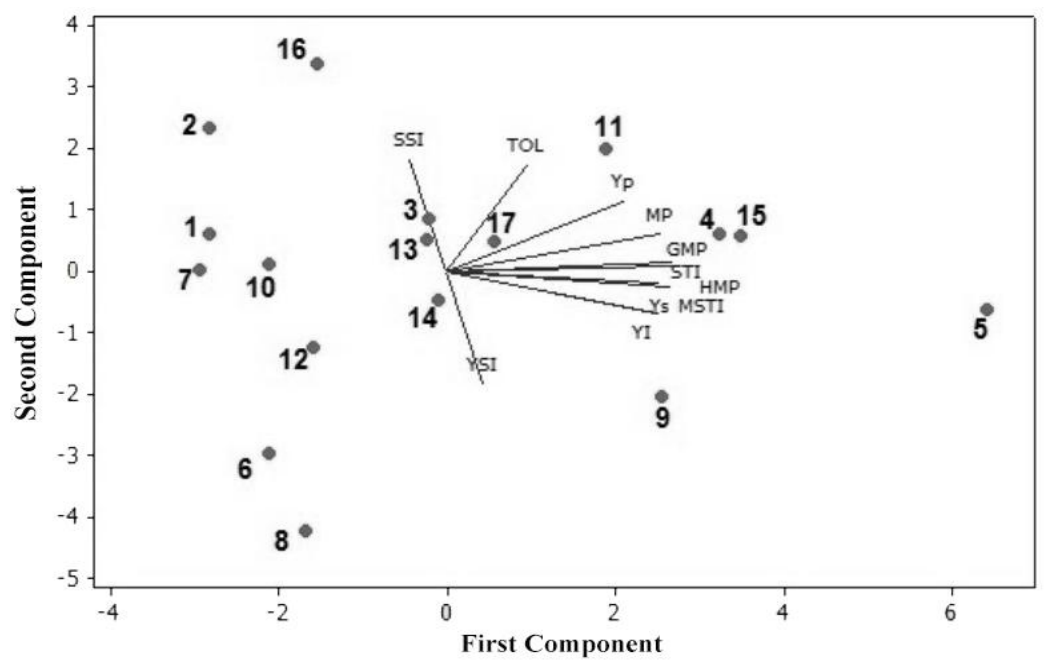

Fig. 2. Biplot diagram based on the first and second principal components for the seventeen rapeseed cultivars and their drought tolerance indices. 1: SLM 046, 2: Opera, 3: Talaye, 4: Modena, 5: Karaj 1, 6: Karaj 3, 7: Zarfam, 8: Okapi, 9: Savanna, 10: Cooper, 11: Adriana, 12: Champlain, 13: NK Karibik, 14: NK Aviator, 15: NK Octans, 16: Licord and 17: Elite Yp: Yield under normal conditions; Ys: Yield under drought stress conditions; SSI: Stress Susceptibility Index; TOL: Tolerance; MP: Mean Productivity; YI: Yield Index; YSI: Yield Stability Index; STI: Stress Tolerance Index; GMP: Geometric Mean Productivity; HMP: Harmonic Mean Productivity; MSTI: Modified Stress Tolerance Index

Table 6. Physiological indices and water use efficiency measured in seventeen rapeseed cultivars under normal and drought stress conditions

\begin{tabular}{lllllllll}
\hline \multirow{2}{*}{ Cultivar } & \multicolumn{2}{c}{ RWC (\%) } & \multicolumn{2}{c}{ RWL } & \multicolumn{2}{c}{ ELWL } & WUE (Kg. ${ }^{-3}$ ) \\
\cline { 2 - 8 } & Normal & Stress & Normal & Stress & Normal & Stress & Normal & Stress \\
\hline SLM 046 & 90.3 & 77.0 & 0.15 & 0.20 & 0.14 & 0.21 & 2.6 & 1.3 \\
Opera & 84.3 & 73.2 & 0.32 & 0.15 & 0.29 & 0.16 & 3.2 & 1.1 \\
Talaye & 89.3 & 86.6 & 0.22 & 0.06 & 0.20 & 0.07 & 3.6 & 2.0 \\
Modena & 86.9 & 83.2 & 0.28 & 0.19 & 0.24 & 0.27 & 4.4 & 2.9 \\
Karaj 1 & 86.0 & 78.5 & 0.24 & 0.18 & 0.20 & 0.15 & 4.7 & 3.9 \\
Karaj 3 & 85.2 & 78.5 & 0.29 & 0.10 & 0.28 & 0.16 & 1.9 & 2.0 \\
Zarfam & 84.9 & 80.5 & 0.20 & 0.23 & 0.17 & 0.27 & 2.4 & 1.4 \\
Okapi & 89.0 & 80.0 & 0.23 & 0.16 & 0.19 & 0.16 & 1.8 & 2.3 \\
Savana & 85.1 & 78.3 & 0.19 & 0.11 & 0.19 & 0.13 & 3.4 & 3.2 \\
Cooper & 83.2 & 69.5 & 0.21 & 0.14 & 0.17 & 0.20 & 2.7 & 1.6 \\
Adriana & 85.4 & 79.3 & 0.14 & 0.17 & 0.14 & 0.24 & 4.6 & 2.3 \\
Champlain & 90.1 & 74.6 & 0.19 & 0.17 & 0.17 & 0.24 & 2.4 & 1.9 \\
NK Karibik & 87.1 & 66.7 & 0.17 & 0.14 & 0.17 & 0.16 & 3.4 & 2.1 \\
NK Aviator & 82.6 & 81.3 & 0.13 & 0.13 & 0.14 & 0.16 & 3.1 & 2.3 \\
NK Octans & 87.8 & 84.1 & 0.37 & 0.28 & 0.29 & 0.20 & 4.5 & 3.0 \\
Licord & 84.2 & 72.4 & 0.24 & 0.16 & 0.21 & 0.19 & 4.2 & 1.2 \\
Elite & 83.0 & 76.2 & 0.17 & 0.15 & 0.15 & 0.16 & 3.6 & 2.3 \\
\hline HSD (0.05) & 8.30 & 10.20 & 0.18 & 0.13 & 0.10 & 0.08 & 0.43 & 0.50 \\
\hline \multicolumn{7}{c}{ RWC: Relative Water Content; RWL: Relative Water Loss; ELWL: Excised Leaf Water Loss; }
\end{tabular}

generally showed high RWC under stress conditions; however, no strong association was found between drought tolerance and RWC. It seems that the drought tolerant cultivars may more efficiently be able to protect themselves against water loss and adjust osmotic pressure under drought stress leading to less yield reduction. Taken together, the physiological indices were not the profound indicators for drought tolerance improvement in rapeseed. 
Majidi et al. [34] also reported that RWC is not a reliable criterion for drought tolerance in rapeseed because of low heritability, however positive correlation was found between RWC and STI.

In arid and semi-arid regions where water shortage is the major limitation of rapeseed production, the optimal achievement of a given breeding program is to identify drought tolerant genotypes with high water use efficiency (WUE). Significant variation among the rapeseed cultivars was found for WUE under both normal and drought stress conditions. Also, WUE significantly decreased under stressful environments. The results revealed that the cultivars with high values of the reliable yieldbased indicators such as GMP and STI, showed high WUE. The cultivars Karaj 1 and Okapi had the highest and lowest WUE in normal conditions, respectively. Under drought stress conditions, Karaj 1 and Opera were the cultivars with the highest and lowest WUE, respectively (Table 6).

\section{CONCLUSION}

The rapeseed cultivars significantly varied for seed yield as well as the yield-based and physiological indices. This study revealed that STI, MP, GMP, HMP, MSTI and YI as well as water use efficiency were the reliable indicators for screening drought tolerant rapeseed cultivars. The 3-D plot and biplot analysis showed that the cultivars Karaj 1, NK Octans and Modena were the high yielding drought tolerant rapeseed cultivars. It should be noted that this study was conducted during one growing season in one location only. Therefore, it is required to repeat this experiment over several years and locations in order to obtain more accurate and robust results.

\section{ACKNOWLEDGEMENTS}

The authors would like to thank Shiraz University for funding this research.

\section{COMPETING INTERESTS}

Authors have declared that no competing interests exist.

\section{REFERENCES}

1. Din J, Khan SU, Ali I, Gurmani AR. Physiological and agronomic response of canola varieties to drought stress. J Anim Plant Sci. 2011;21:78-82.
2. Malekshahi F, Dehghani H, Alizadeh B. A study of drought tolerance indices in Canola (Brassica napus L.) genotypes. J Sci Technol Agric Nat Resour. 2009;13: 77-90.

3. Shirani-Rad $\mathrm{AH}$, Abbasian A. Evaluation of drought tolerance in rapeseed genotypes under non-stress and drought stress conditions. Not Bot Horti Agrobo. 2011;39: 164-171.

4. Aliakbari $M$, Razi $H$, Kazemeini SA. Evaluation of drought tolerance in rapeseed (Brassica napus L.) cultivars using drought tolerance indices. Int $\mathrm{J} \mathrm{Adv}$ Biol Biomed Res. 2014;2:696-705.

5. Robertson MJ, Holland JF. Production risk of canola in the semi-arid subtropics of Australia. Aus J Agric Res. 2004;55:525538.

6. Ramirez-Vallejo P, Kelly JD. Traits related to drought resistance in common bean. Euphytica. 1998;99:127-136.

7. Mitra J. Genetics and genetic improvement of drought resistance in crop plants. Curr Sci. 2001;80:758-763.

8. Fischer RA. Maurer R. Drought resistance in spring wheat cultivars. I. Grain yield responses. Aus J Agric Res. 1978;29:897912.

9. Rosielle AA, Hamblin J. Theoretical aspects of selections for yield in stress and non-stress environments. Crop Sci. 1981; 21:943-946.

10. Bouslama M, Schapaugh WT. Stress tolerance in soybean. Part 1: Evaluation of three screening techniques for heat and drought tolerance. Crop Sci. 1984;24:933937.

11. Fernandez GCJ. Effective selection criteria for assessing plant stress tolerance. In Kuo CG (ed.) Proceedings of the International Symposium "Adaptation of Vegetables and Other Food Crops in Temperature and Water Stress. AVRDC, Taiwan; 1992.

12. Farshadfar E, Sutka J. Screening drought tolerance criteria in maize. Acta Agron Hung. 2002;50:411-416.

13. Lin CS, Binns MR, Lefkovitch LP. Stability analysis: Where do we stand? Crop Sci. 1986;26:894-900.

14. Gavuzzi P, Rizza F, Palumbo M, Campanile RG, Ricciardi GL, Borghi B. Evaluation of field and laboratory predictors of drought and heat tolerance in winter cereals. Can J Plant Sci. 1997;77: 523-531. 
15. Yarnia M, Arabifard N, Rahimzadeh Khoei $\mathrm{F}$, Zandi P. Evaluation of drought tolerance indices among some winter rapeseed cultivars. Afr J Biotechnol. 2011;10:1091410922.

16. Blum A. Drought resistance, water-use efficiency, and yield potential- are they compatible, dissonant, or mutually exclusive? Aus J Agric Res. 2005; 56:1159-1168.

17. Blum A. Plant breeding for stress environments. CRC Press, Inc; 1988.

18. Clarke JM, McCaig TN. Excised- leaf water retention capability as an indicator of drought resistance of Triticum genotypes. Can J Plant Sci. 1982;62:571-578.

19. Manette AS, Richard CJ, Carver BF, Mornhinweg DW. Water relations in winter wheat as drought resistance indicators. Crop Sci. 1988;28:526-531.

20. Xing $H$, Tan L, An L, Zhao Z, Wang S, Zhang $C$. Evidence for the involvement of nitric oxide and reactive oxygen species in osmotic stress tolerance of wheat seedlings: Inverse correlation between leaf abscisic acid accumulation and leaf water loss. Plant Growth Regul. 2004;42:61-68.

21. Clarke TC, Parkin GW, Ferre TPA. Soil water content. In: Carter MR, Gregorich EG (Eds). Soil sampling and methods of analysis. CRC Press; 2008.

22. Cooper PJM, Gregory PJ, Tully D, Harrls HC. Improving water use efficiency of annual crops /in the rainfed farming systems of West Asia and North Africa. Exp Agric. 1987;23:113-158.

23. Barrs HD. Determination of water deficits in plant tissues. In: T.T. Kozolvski (Ed.), Water Deficits and Plant Growth, Academic Press; 1968.

24. Golabadi MA, Arzani SA, Maibody M. Assessment of drought tolerance in segregating populations in durum wheat. Afr J Agric Res. 2006;1:162-171.

25. Yasir TA, Chen $X$, Tian L, Condon AG, Hu $Y$. Screening of Chinese bread wheat genotypes under two water regimes by various drought tolerance indices.
Australian Journal of Crop Science. 2013; 7:2013-2015.

26. Mohammadi M, Karimizadeh FandAbdipour M. Evaluation of drought tolerance in bread wheat genotypes under dryland and supplemental irrigation conditions. Aus J Crop Sci. 2011;5:487493.

27. Naghavi MR, Pouraboughadareh A, Khalili $M$. Evaluation of drought tolerance indices for screening some of corn (Zea mays L.) cultivars under environmental conditions. Not Sci Biol. 2013;5:388-393.

28. Rahimi M, Dehghani $H$, Rabiei $B$, Tarang AR. Evaluation of rice segregating population based on drought tolerance criteria and biplot analysis. Int J Agric Crop Sci. 2013;5:194-199.

29. Khalili M, Naghavi MR, Pour Aboughadareh A, Talebzadeh SJ. Evaluating of drought stress tolerance based on selection indices in spring canola cultivars (Brassica napus L.). J Agric Sci. 2012;4:78-85.

30. Farshadfar E, Elyasi P. Screening quantitative indicators of drought tolerance in bread wheat (Triticum aestivum L.) landraces. Eur J Exp Biol. 2012;2:577-584.

31. Cicek N, Cakirlar $\mathrm{H}$. The effect of salinity on some physiological parameters in two maize cultivars. Bulg J Plant Physiol. 2002; 28:66-74.

32. Gunes A, Inal A, Adak MS, Bagci EG, Cicek N, Eraslan F. Effect of drought stress implemented at pre-or post-anthesis stage on some physiological parameters as screening criteria in chickpea cultivars. Russ J Plant Physiol. 2008;55: 59-67.

33. Farshadfar E, Ghasemi M, Rafii F. Evaluation of physiological parameters as a screening technique for drought tolerance in bread wheat. J Biodiv Envir Sci. 2014;4:175-186.

34. Majidi MM, Rashidi F, Sharafi F. Physiological traits related to drought tolerance in Brassica. Int $\mathrm{J}$ Plant Prod. 2015;9:541-560.

(C) 2017 Bakhtari et al.; This is an Open Access article distributed under the terms of the Creative Commons Attribution License (http://creativecommons.org/licenses/by/4.0), which permits unrestricted use, distribution, and reproduction in any medium, provided the original work is properly cited.

Peer-review history:

The peer review history for this paper can be accessed here: http://sciencedomain.org/review-history/19259 